\title{
Contraceptive use and quality of life among women of reproductive age, attending a general outpatient clinic in a Nigerian tertiary hospital
}

\author{
Tawakalit O. Salam*, Olushola A. Mosuro, Sufiyan A. Muyibi, Adedotun A. Adetunji
}

Department of Family Medicine, University College Hospital, Ibadan, Nigeria

Received: 07 May 2020

Accepted: 01 June 2020

\section{*Correspondence:}

Dr. Tawakalit O. Salam,

E-mail: tawakalit.salam@uch-ibadan.org.ng

Copyright: () the author(s), publisher and licensee Medip Academy. This is an open-access article distributed under the terms of the Creative Commons Attribution Non-Commercial License, which permits unrestricted non-commercial use, distribution, and reproduction in any medium, provided the original work is properly cited.

\begin{abstract}
Background: In Sub-Saharan Africa, unplanned pregnancies, sexually transmitted infections (STIs) and low use of modern contraceptives are major reproductive health problems affecting women of reproductive age. However, there is evidence of an increase in contraceptive use over the past decade. This study was carried out to assess the pattern of contraceptive use, and its association with quality of life among women of reproductive age, attending a general outpatient clinic, at the University College Hospital (UCH), Ibadan, Nigeria.

Methods: A descriptive, cross-sectional study conducted with 323 women aged 15-49 years for three months. Data were retrieved using a semi-structured questionnaire and analyzed using the Statistical Package for Social Sciences (SPSS) version 23.

Results: The mean age of the participants was $34.9 \pm 8$ years. The prevalence of contraceptive use was $43.7 \%$, and out which, 34.4\% accounted for modern methods. At least $72.4 \%$ ever heard about a method of contraceptive. Male condom was the most heard $(96.6 \%)$ and most used $(39.0 \%)$ contraceptive method. Majority of the quality of life parameters had higher mean scores, with significant mean values in vitality and social functioning categories among contraceptive users $(72.41 \pm 14.82$ and $72.07 \pm 18.39$ respectively, $\mathrm{p}=0.029)$ compared with non-contraceptive users.

Conclusions: Despite a higher mean quality of life scores among contraceptive users, less than half of the respondents made use of contraceptives. Therefore, the need for more orientation on the use of contraceptives to promote safe sexual practice and birth control is required.
\end{abstract}

Keywords: Contraceptive use, Modern contraceptives, Quality of life, Women of reproductive age

\section{INTRODUCTION}

Sexual and reproductive conditions account for $18.4 \%$ of the global burden of diseases, and of which a significant percentage occurs among women of reproductive age. ${ }^{1}$ The estimated unintended pregnancy rate in Nigeria was 59 per 1,000 women aged 15-49 years. The incidence of induced abortion was put at 33 per 1,000 women of reproductive age per year, and out of which $56 \%$ of unintended pregnancies were resolved by abortion. ${ }^{2,3}$

Report by the World Health Organisation (WHO) estimated that about 214 million women in developing countries would like to delay or stop childbearing but are not using any form of contraception. ${ }^{4}$ The continuous sensitization of family planning would help to limit or space the number of children through the use of contraceptive methods. ${ }^{5}$

In Nigeria, the prevalence of contraceptive use is about $15 \%$, and this low rate results in the high fertility rate of $5.74 \% .^{6,7}$ It also accounts for the high maternal, infant, and neonatal mortalities. ${ }^{6}$ Contraceptive methods are classified into two i.e. modern and traditional methods. Modern methods include female sterilization, male sterilization, the pill, the intrauterine device (IUD), injectables, implants, male condoms, female condoms, the diaphragm, foam/jelly, the lactational amenorrhoea 
method (LAM), and emergency contraception. While traditional methods include rhythm/Billing's method (periodic abstinence), withdrawal methods and rings/herbs. ${ }^{8}$

Quality of life (QOL) as defined by the World Health Organization (WHO) is referred to an individuals' perception of their position in life in the context of the culture and value systems in which they live and about their goals, expectations, standards and concerns. ${ }^{9}$ Different dimensions of health status have been assessed in relation to the measuring of health-related quality of life, and they include physical functioning, role limitations due to physical health, role limitations due to emotional stress, vitality, mental health, social functioning, bodily pain and general health. ${ }^{10}$

The universal access to reproductive health services is germane to meet up with the 2030 target of the sustainable development goals, to ensure total eradication and improvement with its associated burdens. ${ }^{1,11}$ International studies on the practices and factors that determine contraceptive use among women of reproductive age. However, there is a paucity of data in the developing nations on the quality of life of women in their reproductive age in relation to their contraceptive use. This study, therefore, assessed the pattern of contraceptive use and its association with quality of life among women of reproductive age, attending the GOP clinic, UCH, Ibadan.

\section{METHODS}

This was a descriptive, cross-sectional, hospital-based study which was conducted between July - September 2016, among women of reproductive ages 15-49 years, attending the GOP clinic, UCH, Ibadan. Patients who presented as emergencies, those that have never had sex, and menopausal women were excluded from the study.

The study was carried out at the general out-patient clinic (GOP) of the Department of Family Medicine, University College Hospital (UCH), Ibadan, Oyo State. Ibadan is the capital of Oyo State, and also the largest city in West Africa. Females constitute about $50 \%$ of the population 2.78 million according to the National Population Census 2006. ${ }^{12} \mathrm{UCH}$ is the first Teaching Hospital in the country, founded in 1957, having an 850-bed capacity that serves residents of Ibadan city and its environs. Department of Family Medicine is one of the sub-specialty departments in UCH where Consultants and Resident Doctors deliver health services to the patients, both as out-patients and inpatients.

The questionnaire used was semi-structured and adapted from the questionnaire used for the 2013 Nigeria Demographic Health Survey (NDHS) to obtain necessary information. ${ }^{8}$ Quality of life of the respondents was assessed by using the structured 36-item short-form health survey (SF-36) questionnaire. ${ }^{13}$ An interviewer- administered questionnaire was administered to eligible, consenting and sexually active women of reproductive age 15-49 years attending the GOP clinic, and they were recruited by a systematic random sampling until a sample population of 323 was attained.

\section{Sample size estimation}

Using the Leslie and Kish formula for descriptive studies. $^{14}$

$$
\mathrm{N}=\frac{\mathrm{z}^{2} \mathrm{pq}}{\mathrm{d}^{2}}
$$

$\mathrm{N}=$ minimum sample size

$\mathrm{Z}=$ the standard normal deviate, which corresponds to the $95 \%$ confidence level $=1.96$

$\mathrm{p}=$ the prevalence of current contraceptive use among female traders aged 15-49 years in Ibadan, Oyo State, Nigeria $(25.3 \%){ }^{15}$

$\mathrm{q}=1.0-\mathrm{p}$

$\mathrm{d}=$ level of precision which is 0.05 .

$$
N=\frac{(1.96)^{2}(0.253)(1-0.253)}{(0.05)^{2}}
$$

$\mathrm{N}=290.4$

A total $10 \%$ attrition was added to account for an incomplete response. Therefore, approximately 323 patients were recruited.

\section{Sampling technique}

A systematic random sampling technique was employed. With a sample size of 323 , the sampling interval was calculated by dividing the average total number of patients to be seen over the study period by the sample size. This gave a sampling interval of 4 . An independent observer did a selection of the first patient by the simple random technique (balloting). An average of five or six patients was recruited per day.

\section{Data collection}

Semi-structured interviewer-administered questionnaires were used by a trained research assistant in the department of family medicine, at the general out-patient clinic (GOP) of the University College Hospital (UCH), Ibadan, Nigeria.

\section{Statistical analysis}

Raw data were entered on the prepared template of SPSS (statistical package for social sciences) version 23. Contraceptive use was dichotomized into current use and non-use. The quality of life was analyzed according to its eight dimensions (the physical functioning, role limitations due to physical health, role limitations due to emotional stress, vitality, mental health, social 
functioning, bodily pain and general health), and also categorized into the two main domains (physical and mental domains). Scoring of the SF-36 follows a threestep procedure: item recoding, raw scale score computing, and transformed scale score computing. The item-recoding procedure involved taking the manually inputted raw pre-coded data and assigning a recoded value to each item score. Once the data had been recoded, a raw scale score was calculated as a simple algebraic sum of the item responses for a particular scale. Once the raw scale score had been calculated, it was then transformed to a 0-100 scale; with a higher score indicating a better quality of life.

The scores of the two summary measures (the physical and mental quality of life domains) were dichotomized as 'worse than average' or 'average or better', based on the average of the respective scale components. Mean and standard deviations were used to summarize quantitative variables while frequencies and percentages were used for qualitative data. Chi-square was used to test for association between categorical variables. Independent ttest was used to compare categorical variables with continuous variables. Level of significance was set at $5 \%$.

\section{RESULTS}

A total of 323 participants were recruited, and among these participants, $40(12.4 \%)$ were below 25 years. The mean age of the women was $34.9 \pm 8$ years. The modal age group was found in patients between ages 25-34 years. Majority $208(64.4 \%)$ of the participants had tertiary education, while $31(9.6 \%)$ had at most a primary school education. Many of the participants were married $243(75.2 \%)$ (Table 1).

Table 1: Demographic characteristics of women of reproductive age, attending GOP clinic.

\begin{tabular}{|lll|}
\hline Characteristics & $\begin{array}{l}\text { Frequency } \\
(\mathbf{N}=323)\end{array}$ & Percentage \\
\hline Age in groups (years) & & \\
\hline $15-24$ & 40 & $12.4 \%$ \\
\hline $25-34$ & 122 & $37.8 \%$ \\
\hline $35-44$ & 113 & $35.0 \%$ \\
\hline $45-54$ & 48 & $14.8 \%$ \\
\hline Highest educational level & & \\
\hline $\begin{array}{l}\text { No formal education/ } \\
\text { primary }\end{array}$ & 31 & $9.6 \%$ \\
\hline Secondary & 84 & $26.0 \%$ \\
\hline Tertiary & 208 & $64.4 \%$ \\
\hline Marital status & & \\
\hline Unmarried & 80 & $24.8 \%$ \\
\hline Married & 243 & $75.2 \%$ \\
\hline Religion & & \\
\hline Catholics & 18 & $5.6 \%$ \\
\hline Other Christian & 202 & $62.5 \%$ \\
\hline Islam & 103 & $31.9 \%$ \\
\hline
\end{tabular}

\begin{tabular}{|lll|}
\hline Characteristics & $\begin{array}{l}\text { Frequency } \\
(\mathbf{N}=323)\end{array}$ & Percentage \\
\hline Ethnic group & & \\
\hline Yoruba & 268 & $83.0 \%$ \\
\hline Igbo & 29 & $9.0 \%$ \\
\hline Hausa & 6 & $1.9 \%$ \\
\hline Others & 20 & $6.1 \%$ \\
\hline Occupation & & \\
\hline Unemployed & 81 & $24.8 \%$ \\
\hline Employed & 242 & $75.2 \%$ \\
\hline Income & & \\
\hline Below $N 18,000$ & 144 & $44.6 \%$ \\
\hline N18,001- $\$ 49,000$ & 83 & $25.7 \%$ \\
\hline Above $¥ 49,000$ & 96 & $29.7 \%$ \\
\hline
\end{tabular}

The total contraceptive used was found in 141 (43.7\%) of the total population of women of reproductive age, attending the GOP Clinic, at the University College Hospital, Ibadan. Out of this 141 (43.7\%) participants, $111(34.4 \%)$ used modern contraceptive methods, while $30(9.3 \%)$ used traditional methods (Figure 1).

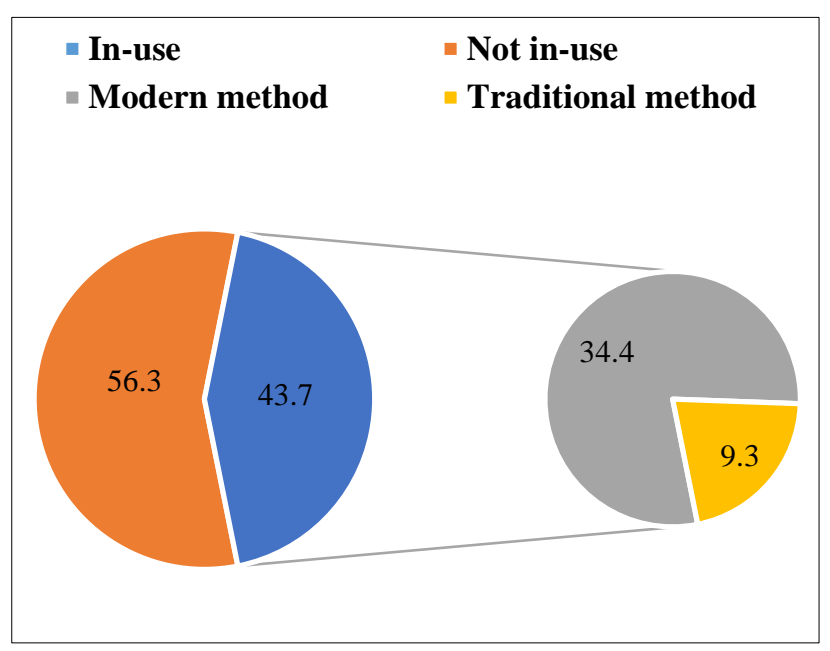

Figure 1: Contraceptive use among women of reproductive age, attending the GOP clinic.

Note: Traditional methods: billing/rhythm; withdrawal; rings and herbs.

Modern methods: female sterilization, male sterilization, the pills, the intrauterine device (IUD), injectables, implants, male condoms, female condoms, the diaphragm, foam/jelly, the lactational amenorrhoea method (LAM), and emergency pills.

The awareness and pattern of contraceptive method use among the participants are as follows; Male condom was the most $(39.0 \%)$ used contraceptive method, followed by withdrawal $(17.7 \%)$, injectable $(11.3 \%)$, IUD (11.3\%), LAM $(7.1 \%)$, implant $(5.7 \%)$, emergency pills $(4.3 \%)$, rhythm/billing method $(3.5 \%)$, oral pills $(2.8 \%)$, female sterilization $(2.1 \%)$, and rings/herbs $(1.4 \%)$. All the 
participants had heard about at least a method of contraception, and female sterilization (72.4\%) was the least heard method, while male condom was the most heard (96.6\%). Knowledge of foam/jelly, female condom, diaphragm, beads and male sterilization did not translate to their use (Figure 2).

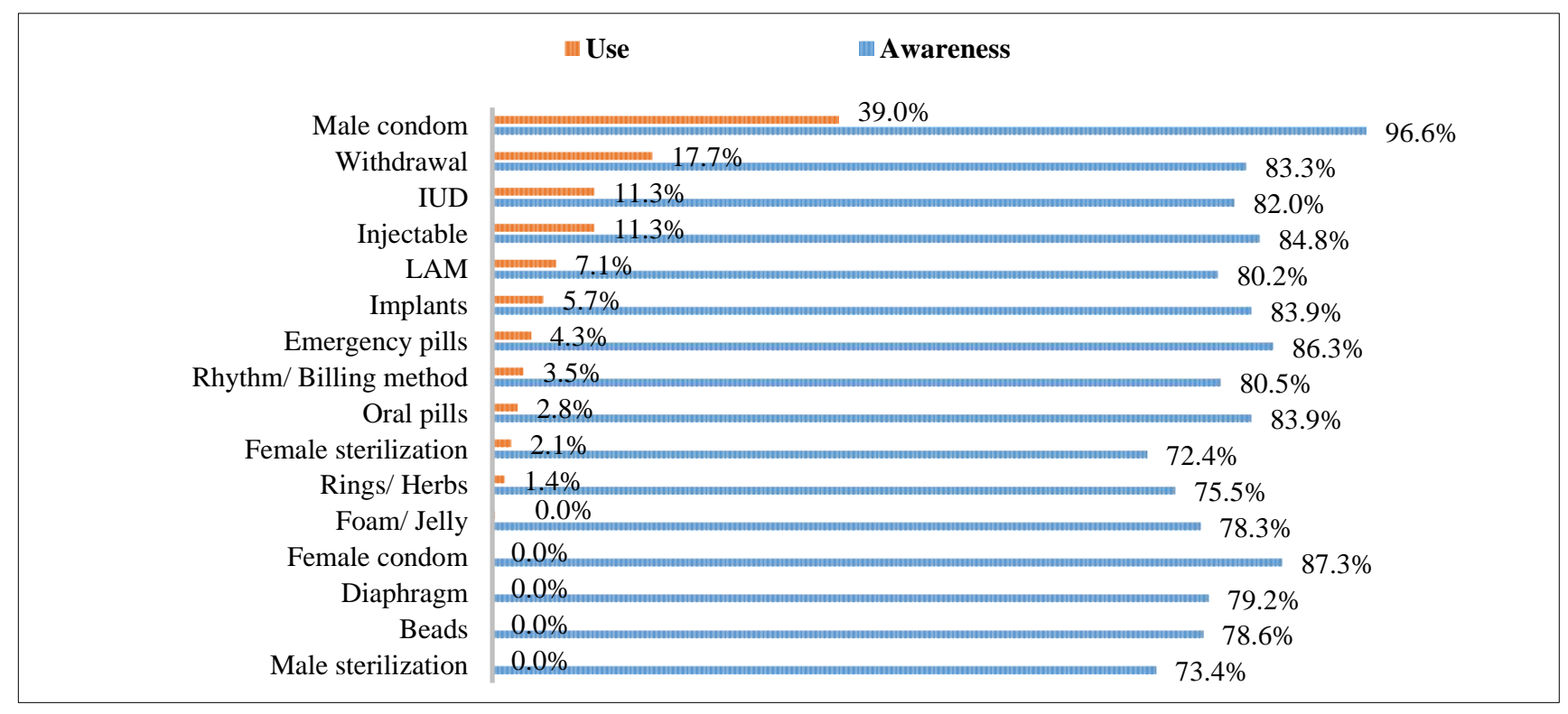

Figure 2: Contraceptive awareness and use among women of reproductive age, attending the GOP clinic.

Note: intrauterine device (IUD), lactational amenorrhoea method (LAM). Figure 2 shows the pattern of contraceptive method ever heard and used by women of reproductive age, attending the GOP clinic.

At least $72.4 \%$ ever heard about a method of contraceptive. The male condom was the most heard $(96.6 \%)$ and most used (39.0\%). Knowledge of foam/jelly, female condom, diaphragm, beads and male sterilization did not translate to their use.

The pattern of sources of information/contraceptive method used among the participants showed that the commonest source of information was from friends and relatives $(85 \%)$, followed by television $(61.9 \%)$ and radio $(61.3 \%)$. Among the participants that were currently using a contraceptive method, the majority (33.4\%) of them got them from government-owned facilities, followed by the pharmacy/medicine stores (Table 2).

Most $(65.3 \%)$ of the participants had used contraceptive methods of choice for between 1- 5 years (Table 3 ). Some of the reasons for the non-use of contraceptive methods in $182(56.3 \%)$ participants included a readiness to get pregnant $(40.7 \%)$, which was the most implicated reason for non-use.

This was followed by the fear of side effects/health concerns $(29.1 \%)$, infrequent sex $(9.9 \%)$ and partner's disapproval $(5.5 \%)$. None of the participants was using contraceptive method due to inconvenience, lack of access to uptake or follow up, marital dissolution, or cost (Table 4).

Table 2: Pattern of sources of information/ contraceptive method used among the participants.

\begin{tabular}{|lcc|}
\hline $\begin{array}{l}\text { Contraceptive methods } \\
\text { used }\end{array}$ & Frequency & Percentage \\
\hline Source of information & & \\
\hline Friends and relatives & 276 & $85.4 \%$ \\
\hline Television & 200 & $61.9 \%$ \\
\hline Radio & 198 & $61.3 \%$ \\
\hline Newspaper & 98 & $30.3 \%$ \\
\hline Internets & 90 & $27.9 \%$ \\
\hline Posters & 88 & $27.2 \%$ \\
\hline Leaflets & 87 & $26.9 \%$ \\
\hline Phone messages & 83 & $25.7 \%$ \\
\hline $\begin{array}{l}\text { Town criers/Health } \\
\text { personnels }\end{array}$ & 52 & $16.1 \%$ \\
\hline Source of contraceptive method used & \\
\hline $\begin{array}{l}\text { Government hospitals/ } \\
\text { centres }\end{array}$ & 101 & $33.4 \%$ \\
\hline $\begin{array}{l}\text { Pharmacy/medicine } \\
\text { stores }\end{array}$ & 99 & $32.8 \%$ \\
\hline Friends/relatives/partners & 78 & $25.8 \%$ \\
\hline Private hospitals/centres & 24 & $8.0 \%$ \\
\hline
\end{tabular}

Multiple responses. 
Table 3: Duration of contraceptive method currently used among the participants.

\begin{tabular}{|c|c|c|c|}
\hline \multirow{2}{*}{$\begin{array}{l}\text { Duration of currently used } \\
\text { method }\end{array}$} & \multicolumn{3}{|c|}{ Currently used Contraceptive method $(n=141)$} \\
\hline & Modern n (\%) & Traditional n (\%) & All methods n (\%) \\
\hline$<1$ year & $23(20.7 \%)$ & $1(3.3 \%)$ & $24(17.0 \%)$ \\
\hline $1-2$ years & $36(32.5 \%)$ & $12(40.0 \%)$ & $48(34.0 \%)$ \\
\hline 3-5 years & $37(33.3 \%)$ & $7(23.4 \%)$ & $44(31.3 \%)$ \\
\hline$>5$ years & $15(13.5 \%)$ & $10(33.3 \%)$ & $25(17.7 \%)$ \\
\hline Total & $111(78.7 \%)$ & $30(21.3 \%)$ & $141(100.0 \%)$ \\
\hline
\end{tabular}

Table 4: Reasons for non-use of contraceptive methods among women of reproductive age, attending GOP.

\begin{tabular}{|lll|}
\hline Reasons for non-use of contraceptive method & Frequency (n=182) & Percentage (\%) \\
\hline Wanted to become pregnant & 74 & $40.7 \%$ \\
\hline Side effect/health concern & 53 & $29.1 \%$ \\
\hline Infrequent sex/husband away & 18 & $9.9 \%$ \\
\hline Partner disapproved & 10 & $5.5 \%$ \\
\hline Don't know/no reason & 18 & $9.9 \%$ \\
\hline Up to God/religious reasons & 7 & $3.9 \%$ \\
\hline Became pregnant & 1 & $0.5 \%$ \\
\hline Wanted more effective method & 1 & $0.5 \%$ \\
\hline
\end{tabular}

Table 5: T-test statistics to compare the means of the quality of life among contraceptive users and non-users $(\mathrm{N}=323)$.

\begin{tabular}{|c|c|c|c|c|}
\hline \multirow{2}{*}{ Variables } & \multicolumn{2}{|c|}{ Contraceptive use mean (SD) } & \multirow{2}{*}{ t-test score } & \multirow{2}{*}{ p-value } \\
\hline & Yes n $(\%)$ & No $n(\%)$ & & \\
\hline \multicolumn{5}{|l|}{ Category of quality of life } \\
\hline Physical functioning & $91.70(11.54 \%)$ & $89.14(14.61 \%)$ & 1.759 & 0.089 \\
\hline Role limited due to physical health & $70.04(40.67 \%)$ & $66.85(41.63 \%)$ & 0.69 & 0.491 \\
\hline Role limited due to emotional problems & $54.85(49.30 \%)$ & $54.95(49.15 \%)$ & -0.02 & 0.986 \\
\hline Energy/ fatigue & $72.41(14.82 \%)$ & $69.07(12.60 \%)$ & 2.15 & $0.029 *$ \\
\hline Emotional well-being & $78.13(13.60 \%)$ & $78.04(13.94 \%)$ & 0.05 & 0.957 \\
\hline Social functioning & $72.07(18.39 \%)$ & $67.10(18.91 \%)$ & 2.37 & $0.018 *$ \\
\hline Pain & $70.50(29.71 \%)$ & $65.19(30.41 \%)$ & 1.57 & 0.117 \\
\hline General health & $74.65(15.04 \%)$ & $72.62(13.91 \%)$ & 1.26 & 0.211 \\
\hline
\end{tabular}

$* \mathrm{p}$ is $<0.05$ (statistically significant).

Table 7: Chi-square test of association between contraceptive use and quality of life.

\begin{tabular}{|c|c|c|c|c|}
\hline \multirow{2}{*}{ Quality of life domains } & \multicolumn{2}{|c|}{ Contraceptive use ( $\mathbf{N}=323)$} & \multirow{2}{*}{ Chi Sq $\left(\chi^{2}\right)$} & \multirow{2}{*}{ p-value } \\
\hline & Yes n $(\%)$ & No n $(\%)$ & & \\
\hline \multicolumn{5}{|l|}{ Physical domain } \\
\hline Worse than average & $17(12.1 \%)$ & $27(14.8 \%)$ & \multirow{2}{*}{0.521} & \multirow{2}{*}{0.470} \\
\hline Average or better & $124(87.9 \%)$ & $155(85.2 \%)$ & & \\
\hline \multicolumn{5}{|l|}{ Mental domain } \\
\hline Worse than average & $27(19.1 \%)$ & $48(26.4 \%)$ & \multirow{2}{*}{2.326} & \multirow{2}{*}{0.127} \\
\hline Average or better & $114(80.9 \%)$ & $134(73.6 \%)$ & & \\
\hline
\end{tabular}

The mean of the eight categories of health-related quality of life was relatively higher among contraceptive users as compared with non-users, except in the category of role limited due to emotional problems. A statistically significant difference was found in the mean of energy/fatigue $(\mathrm{t}=2.5 ; \mathrm{p}=0.029)$ and social functioning $(\mathrm{t}=321 ; \mathrm{p}=0.018)$ alone (Table 5).

Following the grouping of quality of life into the physical and mental domain, its test of association with 
contraceptive use indicated no significant association between them (Table 6).

\section{DISCUSSION}

The results from this index study on contraceptive use and quality of life among women of reproductive age, attending a general outpatient clinic, University College Hospital, Ibadan, revealed an overall prevalence of contraceptive users in $43.7 \%$ of the total population. Out of these contraceptive users, $34.4 \%$ engaged in the modern method of contraceptive use, while $9.3 \%$ practiced traditional method.

This result is higher than the study report in the year 2013 and 2015 respectively on the overall prevalence of contraceptive use in Sub-Saharan Africa (19\%) and Nigeria $(15 \%) .8,16$

The participants' age ranged from 19 to 49 years which is in keeping with the WHO definition of women of reproductive age (15 to 49 years). ${ }^{17}$ The majority $(37.8 \%$ ) of the participants were between the ages of 25- 34 years, with a mean age of $34.9 \pm 8$ years. This is quite similar to the study carried out by Adeyemi et al. on contraceptive prevalence among women of the reproductive age group in Ogbomoso, Nigeria. ${ }^{18}$

Most of the respondents had tertiary education $(64.4 \%)$ from this study. This is similar to the Nigeria demographic health survey (NDHS) which reported $62.9 \%$ of the population having at least a secondary school education in Oyo State, Nigeria. ${ }^{8}$

Married women (75.2\%) were twice as more than the unmarried, which is expected in a group of reproductive age. This result is similar to many other studies having up to $97.6 \%, 65.1 \%$, and $61.0 \%$ respectively. ${ }^{19,20}$

The level of awareness of the various methods of contraceptives use found from this study was all above $70 \%$. The least known contraceptive method was female sterilization $(72.4 \%)$ and was used by $2.1 \%$ of the respondents. High level of awareness was found for the male condom, followed by female condom and injectables. However, the majority of the level of awareness found with the various contraceptive methods do not correspond to the level of use. This result agrees with previous studies that have reported imbalance in the level of awareness and knowledge with contraceptive methods being used. ${ }^{8,21,22}$ This, therefore, suggests the presence of some contextual factors that may be responsible for their low usage. The most used contraceptive method obtained from this study was male condom $(39 \%)$, followed by the withdrawal method $(7.7 \%)$, injectables $(11.3 \%)$ and intrauterine device (11.3\%). Studies by Adeyemi et al, and Chima et al, also reported similar but higher use of the male condom in $74.8 \%$ and $81 \%$ respectively among their study participants. ${ }^{18,23}$ However, Ajayi et al, reported a higher pattern of current contraceptive use for rhythm method/standard day method $(26.4 \%)$, followed by withdrawal method $(16.8 \%)$, and then male condom in $17.8 \%$ of their respondents. ${ }^{24}$ The high use of male condom found from this study might be as a result of its dual function i.e., against protection from sexually transmitted disease and prevention of unplanned pregnancies. The permanent form of contraception i.e., female and male sterilization was barely opted for which might be due to sociocultural influence.

A 10-year review study carried out by Muhammad and Maimuna reported injectables to be the most commonly used method. ${ }^{25}$ The use of injectable contraceptives in women of reproductive age has been reported to be due to the avoidance of being detected by their spouses. ${ }^{26}$

The sources of information garnered by the participants on various contraceptive methods were commonest among friends and relatives $(85.4 \%)$. This result is contrary to the report of health care personnel in hospitals $(46.8 \%)$ by Adeyemi et al, and nurses (42.9\%) by Okunade et al, However, a similar result stating information from friends $(73.7 \%)$ was reported by Abiodun and Balogun. ${ }^{18,20,27}$ The variance concerning the sources of information could be as a result of the type of settlement i.e. rural and urban area settings.

Also, in this study, the major source of contraceptive uptake method of choice was obtained from government facilities $(33.4 \%)$, followed by the pharmacy $(32.8 \%)$, friends and relatives $(25.8 \%)$ and private facilities $(8.0 \%)$. This finding could be due to the provisioning of contraceptives, which are given for free in public health facilities by the Federal Government of Nigeria. ${ }^{8,28}$

Furthermore, many of these participants (34\%) have reported the use of contraceptives for one to two years, and $31.3 \%$ for three to five years. This is similar to the finding by Olugbenga-Bello et al, who also reported one to five years as the most prevalent duration for use of a method of choice of contraceptive among their study population. ${ }^{29}$ It can, therefore, be inferred that the women within this study were familiar with their desired choice of contraceptives used.

In 182 participants, a report of discontinuation of contraceptive methods was found primarily as a result of the desire to get pregnant $(40.7 \%)$, followed by the concern of side effects $(29.1 \%)$. This result corresponds with the findings from other previous studies. ${ }^{30-33}$

The assessment of the quality of life of the participants using the structured 36-item short-form health survey (SF-36) questionnaire revealed a higher mean score in all the categories of quality of life among contraceptive users when compared with non-users except in the category of role limited due to emotional problems. The mean category scores of energy/fatigues and that of social functioning showed a statistically significant difference 
$(\mathrm{p}=0.029$ and $\mathrm{p}=0.018$ respectively) among contraceptive users when compared with non-users. This is similar to study by Rayamajhi et al, which found an increase in all the domain scores of quality of life except for environmental domain score among contraceptive users than the non-users. ${ }^{34} \mathrm{~A}$ significant increase was also seen which might be due to the WHO tool used as opposed to the SF-36 used in this index study.

Furthermore, no significant association was found between contraceptive use on the physical and mental domain of quality of life. Williams et al. in their study, however, found a significant difference in both average physical $(\mathrm{p}<0.001)$ and mental $(\mathrm{p}<0.001)$ health-related quality of life (HRQoL) among women using different contraceptive methods. However, contraceptive users were more likely to report average or better mentalHRQoL than non-users. ${ }^{35}$ One of the reasons for this disparity in the level of significance could be as a result of racial difference.

Limitations of this study was hospital-based, and so, it does not fully capture women of reproductive age living in remote communities that do not seek medical consultation. Use of contraceptives was self-reported, and some of the questions were sensitive which required persistent reassurance of confidentiality and anonymity of respondents. There are different reasons for using contraception, which may result in a differential impact on the quality of life. However, this study only considered contraceptive reason as high maternal morbidity and mortality due to the consequences of unwanted pregnancy was of concern.

\section{CONCLUSION}

This study revealed that more than two-thirds of the participants within their reproductive ages were aware of various contraceptive methods, but did not translate into its good use, as less than half of the participants made use of them. Also, the assessment of the quality of life showed higher mean scores, with significant mean values for energy/fatigue and social functioning categories alone among contraceptive users.

\section{Recommendations}

There should be more advocacies on the use of contraceptives and the benefits it offers in the improvement of health-related quality of life. Adequate health information and education on contraceptive use by health professionals should be ensured, to reduce misconceptions from individuals who were found to be the most common source of information within this environment.

\section{ACKNOWLEDGMENTS}

Authors would like to acknowledge the staff of the Department of Family Medicine, University College
Hospital, Ibadan, Nigeria, for their support during the data collection. All the participants are also appreciated.

Funding: No funding sources

Conflict of interest: None declared

Ethical approval: The study was approved by the Institutional Ethics Committee

\section{REFERENCES}

1. Adongo PB, Tabong PT, Azongo TB, Phillips JF, Sheff MC, Stone AE, et al. A comparative qualitative study of misconceptions associated with contraceptive use in southern and northern ghana. Front Public Health. 2014;2:137.

2. Bankole A, Adewole IF, Hussain R, Awolude O, Singh S, Akinyemi JO. The incidence of abortion in Nigeria. Int Perspect Sexual Reprod Health. 2015;41(4):170-81.

3. Tekelab T, Melka AS, Wirtu D. Predictors of modern contraceptive methods use among married women of reproductive age groups in Western Ethiopia: a community based cross-sectional study. BMC Women's Health. 2015;15(1):52.

4. Family planning: World Health Organization. Available at: https://www.who.int/en/newsroom/fact-sheets/detail/family-planningcontraception. Accessed on $12^{\text {th }}$ March 2020.

5. Singh S, Darroch JE, Ashford LS, Vlassoff M. Adding it up: the costs and benefits of investing in family planning and maternal and newborn health. USA: GUTTMACHER and UNFPA; 2009.

6. Monjok E, Smesny A, Ekabua JE, Essien EJ. Contraceptive practices in Nigeria: literature review and recommendation for future policy decisions. Open Access J Contracept. 2010(1):9-22.

7. United Nations, department of economic and social affairs, population division. World Population Prospects: The 2015 Revision, Key Findings and Advance Tables. Working Paper No. ESA/P/WP.241. New York: United Nations; 2015. Available at: http://esa.un.org/unpd/wpp/publications /files/key_findings_wpp_2015.pdf. Accessed on $15^{\text {th }}$ March 2020.

8. National Population Commission (NPC) [Nigeria] and ICF International. Nigeria Demographic and Health Survey 2013. Abuja, Nigeria, and Rockville, Maryland, USA: NPC and ICF International. 2014.

9. Romero M, Vivas-Consuelo D, Alvis-Guzman N. Is Health related quality of life (HRQoL) a valid indicator for health systems evaluation? Springer Plus. 2013;2(1):1-7.

10. Hart PD, Kang M. Reliability of the short-form health survey (SF-36) in physical activity research using meta-analysis. World J Prevent Med. 2015;3(2):17-23.

11. ICSU. Review of targets for the sustainable development goals: the science perspective: International council for science (ICSU); 2015. Available at: http://www.icsu.org/publications/ 
reports-and-reviews/review-of-targets-for-thesustainable-development-goals-the-scienceperspective-2015/SDG-Report.pdf. Accessed on $15^{\text {th }}$ March 2020.

12. Nigeria 2006 Census Figures. National Population Commission. 2006. Available at: http://www.nigeriamasterweb.com/Nigeria06Census Figs.html. Accessed on $12^{\text {th }}$ March 2020.

13. Goertz CM. Scoring the RAND SF-36-item health survey 1.0. Clin Chiro. 1994;1(1):51-9.

14. Charan J, Biswas T. How to calculate sample size for different study designs in medical research? Indian J Psychol Med. 2013;35(2):121-6.

15. Balogun MO, Owoaje ET, Owoaje ET. Contraceptive use among female traders in Ibadan, Nigeria. Trop J Obstet Gynaecol. 2013;30(2):63-71.

16. Pacqué-Margolis S, Cox C, Puckett A, Schaefer L. Exploring contraceptive use differentials in SubSaharan Africa through a health workforce lens. Technical Brief. 2013;11.

17. Sexual and reproductive health: WHO; 2017. Available at: http://www.who.int/reproductive health/topics/infertility/definitions/en/. Accessed on $12^{\text {th }}$ March 2020.

18. Adeyemi AS, Olugbenga-Bello AI, Adeoye OA, Salawu MO, Aderinoye AA, Agbaje MA. Contraceptive prevalence and determinants among women of reproductive age group in Ogbomoso, Oyo State, Nigeria. Open Access J Contracept. 2016;7:3341.

19. Kidayi PL, Msuya S, Todd J, Mtuya CC, Mtuy T, Mahande MJ. Determinants of modern contraceptive use among women of reproductive age in Tanzania: evidence from Tanzania demographic and health survey data. Adv Sex Med. 2015;5(3):43-52.

20. Okunade K, Daramola E, Ajepe A, Sekumade A. A 3-year review of the pattern of contraceptive use among women attending the family planning clinic of a university teaching hospital in Lagos, Nigeria. African J Med Health Sci. 2017;15:69-73.

21. Anguko AA. Determinants of contraceptive use among women of reproductive age in north eastern Kenya. Nairobi: University of Nairobi Institute of Tropical and Infectious Diseases (UNITID); 2014.

22. Asekun-Olarinmoye EO, Adebimpe WO, Bamidele JO, Odu OO, Asekun-Olarinmoye IO, Ojofeitimi EO. Barriers to use of modern contraceptives among women in an inner-city area of Osogbo metropolis, Osun State, Nigeria. Int J Women's Health. 2013;5:647-55.

23. Chimah U, Lawoyin T, Ilika A, Nnebue C. Contraceptive knowledge and practice among senior secondary schools students in military barracks in Nigeria. Nigerian J Clin Pract. 2016;19(2):182-8.

24. Ajayi AI, Adeniyi OV, Akpan W. Use of traditional and modern contraceptives among childbearing women: findings from a mixed methods study in two southwestern Nigerian states. BMC Public Health. 2018;18(1):604.

25. Muhammad Z, Maimuna DG. Contraceptive trend in a tertiary facility in North Western Nigeria: a 10-year review. Nigeria Journal of Basic Clinical Sciences. 2014;11(2):99.

26. Chigbu B, Onwere S, Aluka C, Kamanu C, Okoro O, Feyi-Waboso PJ. Contraceptive choices of women in rural Southeastern Nigeria. Nigerian J Clin Pract. 2010;13(2):195-9.

27. Abiodun OM, Balogun OR. Sexual activity and contraceptive use among young female students of tertiary educational institutions in Ilorin, Nigeria. Contracept. 2009;79(2):146-9.

28. Schwandt HM, Skinner J, Saad A, Cobb L. Doctors are in the best position to know: The perceived medicalization of contraceptive method choice in Ibadan and Kaduna, Nigeria. Patient Educat Counsel. 2016;99(8):1400-5.

29. Olugbenga-Bello AI, Abodunrin OL, Adeomi AA. Contraceptive practices among women in rural communities in South-Western Nigeria. Global J Med Res. 2011;11:2.

30. Idonije BO, Oluba OM, Otamere HO. A study on knowledge, attitude and practice of contraception among secondary school students in Ekpoma, Nigeria. JPCS. 2011;2:22-7.

31. Adogu P, Udigwe I, Udigwe G, Onwasigwe C. Comparative analysis of sexual practice and contraceptive use among student and non-student adolescent girls in Onitsha, Nigeria. Albanian Medical Journal. 2014;4:12-20.

32. Imo CK, Okoronkwo E, Ukoji V. Interaction effect of knowledge and use of contraceptive methods on fertility among Umuahia women of South-Eastern Nigeria. J Culture Society Develop. 2015;5:18-26.

33. Asiimwe JB, Ndugga P, Mushomi J, Manyenye Ntozi JP. Factors associated with modern contraceptive use among young and older women in Uganda; a comparative analysis. BMC Pub Health. 2014;14:926.

34. Rayamajhi RB, Paudel IS, Bhattarai S, Neupane B, Pokharel PK. Practice of contraception and quality of life among Bhutanese refugee women of eastern Nepal. Global J Med Res Interd. 2014;14(2):17-22.

35. Williams SL, Parisi SM, Hess R, Schwarz EB. Associations between recent contraceptive use and quality of life among women. Contracept. 2012;85(3):282-7.

Cite this article as: Salam TO, Mosuro OA, Muyibi SA, Adetunji AA. Contraceptive use and quality of life among women of reproductive age, attending a general outpatient clinic in a Nigerian tertiary hospital. Int J Reprod Contracept Obstet Gynecol 2020;9:2932-9. 